\title{
Objective Quantification of Posterior Capsule Opacification after Cataract Surgery, with Optical Coherence Tomography
}

\author{
Javier Moreno-Montañés, Aurora Alvarez, and Miguel J. Maldonado
}

Purpose. To evaluate posterior capsule opacification (PCO) in humans after cataract surgery with intraocular lens (IOL) implantation, by using optical coherence tomography (OCT-1).

Methods. Sixty-six eyes with PCO and 20 eyes with a normal posterior capsule were analyzed. A 3-mm-long horizontal scan of the posterior capsule was obtained. Measurements at three points and their average were recorded. Intraoperator and interoperator reliabilities were assessed. Investigated was peak intensity (PI) and posterior capsule thickening (PCT), with PCT indicating the distance between two reflectivity spikes, with an approximate axial resolution of $10 \mu \mathrm{m}$. Results were compared with visual acuity (VA) and PCO type.

RESults. Intraoperator reliability was 0.59 and 0.97 for average PI and PCT, respectively. The interoperator concordance correlation coefficient was 0.70 and 0.82 for average PI and PCT, respectively. Median (interquartile range) intensities of the reflectivity spike were $16.88(\mathrm{~dB})$ (range, 12.88-20.41) and 11.9 (8.58-14.28), respectively, in the PCO and control eyes $(P$ $=0.001)$. PCT was found in PCO eyes (median: $86.13 \mu \mathrm{m}$; range, 46.33-115.33), whereas no second spike appeared in control eyes $(P=0.001)$. The area under the receiver operating characteristic curve of the average PCT for differentiating pearl-type from fibrosis-type PCO was $0.87(P=0.001)$. For a cutoff point of $55.3 \mu \mathrm{m}$, the sensitivity was $97.5 \%$, and the specificity was $69 \%$. Worse VA correlated significantly only with larger PCT $\left(r_{\mathrm{o}}=0.66 ; P=0.01\right)$.

Conclusions. OCT-1 appears useful to quantitate PCO. In addition, this system seems to discriminate between different types of PCO. PCT may be a previously unrecognized factor in VA degradation. (Invest Ophthalmol Vis Sci. 2005;46:3999-4006) DOI:10.1167/iovs.04-1531

$P$ osterior capsule opacification (PCO), the most common long-term complication of cataract surgery, is caused by lens epithelial cells that remain in the capsular bag after surgery. The cells migrate, proliferate, and transform, to produce Elschnig's pearls and capsular fibrosis. ${ }^{1}$ These processes do not cause symptoms in the peripheral capsular bag, but encroachment onto the visual axis causes light-scattering and visual deterioration. PCO can be treated by Nd:YAG laser capsulotomy; however, complications such as cystoid macular edema and retinal detachment may develop and the visualization of

From the Department of Ophthalmology, Clínica Universitaria, Facultad de Medicina, Universidad de Navarra, Pamplona, Spain.

Submitted for publication December 30, 2004; revised June 3, 2005; accepted September 19, 2005.

Disclosure: J. Moreno-Montañés, None; A. Alvarez, None; M.J. Maldonado, None

The publication costs of this article were defrayed in part by page charge payment. This article must therefore be marked "advertisement" in accordance with 18 U.S.C. $\$ 1734$ solely to indicate this fact.

Corresponding author: Javier Moreno-Montañés, Department of Ophthalmology, Clínica Universitaria, Universidad de Navarra, Apartado 4209, 31080 Pamplona, Spain; jmoreno@unav.es. the peripheral retina does not improve. In addition, the cost of the cataract surgery increases.

Although the incidence of PCO has decreased because of improved surgical and cortical cleanup techniques, it is still considerable and varies greatly among studies. ${ }^{2-9}$ Cataract extractions are performed on more than 1 million patients annually in the United States, at least a quarter of whom eventually have PCO. ${ }^{10,11}$

Optical coherence tomography (OCT) facilitates high-resolution cross-sectional imaging of tissue in which optical interferometry determines the distance to reflective ocular structures. ${ }^{12}$ OCT has been studied extensively for qualitative and quantitative analysis of retinal disease $\mathrm{s}^{13}$ and nerve fiber layer thickness measurements. ${ }^{14}$ In both modalities, OCT has demonstrated adequate reproducibility. Other applications of OCT in the anterior segment also have been reported. In our previous study, ${ }^{15}$ OCT was useful for evaluating the qualitative and quantitative anatomic outcomes after LASIK. We also demonstrated excellent reproducibility of repeated pachymetric OCT measurements. ${ }^{15}$ OCT can be used to analyze other anterior segment features. ${ }^{16-18}$

The purpose of the present study was to assess PCO using OCT as a noncontact imaging and high-resolution tool to evaluate the efficacy of the procedure for quantifying PCO and its characteristics.

\section{Patients and Methods}

\section{Patient Selection}

We conducted a study using OCT-1 in patients with PCO in the visual axis after cataract surgery. This study was performed over 6 months and included all patients with biomicroscopically detectable PCO that we examined during this period. The control group comprised patients without PCO who were examined during the same period. We excluded patients with active ocular disease or IOL displacement, those who had had a YAG laser posterior capsulotomy, and those who had difficulty with ocular fixation with OCT-1. Patients with an anterior capsulotomy other than capsulorrhexis or cases without overlapping of the capsulorrhexis rim over the anterior optic IOL surface were also excluded.

Sixty-six eyes (56 patients) with the biomicroscopic finding of PCO were included. The patients ranged in age from 18 to 86 years (median age, 71.50 years; interquartile range [IR], 64.75-76 years); 21 were men (median age, 72 years; IR, 65-77 years) and 35 were women (median age, 69 years; IR, $64-76$ years; $P=0.57$; men versus women).

Twenty eyes of 20 consecutive patients (10 men, 10 women) served as the control. These patients had undergone phacoemulsification at our institution without development of biomicroscopically detectable PCO or other complications. All control eyes underwent the same examination as the patients with PCO. Inclusion criteria were Snellen best-corrected visual acuity (BCVA) of 20/20 and myopia or hyperopia less than $4 \mathrm{D}$. If the patients had undergone bilateral cataract surgery, only one eye was randomly included in the control group. The median age of the control group was 76 years (IR, 69.75-77.75; $P=$ 0.01 compared with the PCO group by the Mann-Whitney test). All 


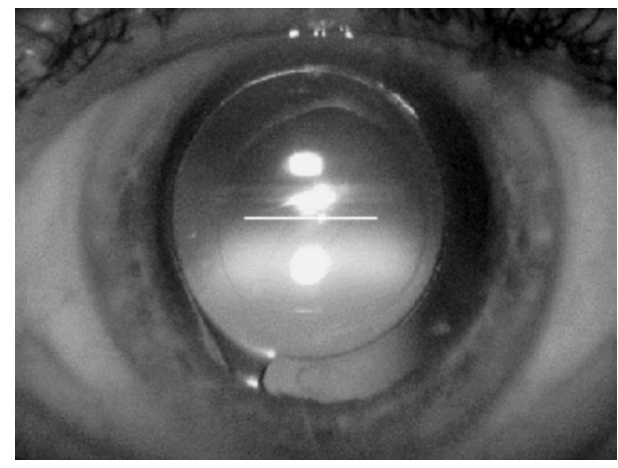

FiguRE 1. The location of the OCT scan is shown (borizontal, light area). The portion of the central posterior capsule that is tomographically imaged measures an average of $3 \mathrm{~mm}$ long and is located over the visual axis

patients provided written informed consent. The clinical research committee of our institution approved the study protocol.

\section{Patient Examination}

All eyes underwent a complete ophthalmic evaluation that included measurement of BCVA, anterior segment biomicroscopy with PCO evaluation (fibrosis-type or pearl-type), ${ }^{19,20}$ and macular visualization with indirect ophthalmoscopy. BCVA was converted to the logarithm of the minimum angle of resolution (logMAR) scale. All patients were examined by one clinician (JM-M). One drop of phenylephrine and tropicamide was instilled to induce mydriasis before OCT.

To compare OCT results with the data from the cataract surgery, we reviewed the patients' charts, and the type of IOL implanted was documented. The months between cataract surgery and evaluation of PCO were calculated.

\section{OCT Examination}

The principles and optical properties of the OCT system have been described previously. ${ }^{21,22}$ The OCT-1 scanner (Carl Zeiss Meditec, Dublin, CA) with the A- 4 software update was used throughout the study. After the pupil was dilated to $4 \mathrm{~mm}$, PCO was measured with the scan profile display. After ensuring central fixation, a 3-mm-long horizontal scan was obtained from the IOL surface and the posterior capsule at the center of the IOL (Fig. 1). Three measurements of each scan were taken: at the center of the scan (fixation point) and $800 \mu \mathrm{m}$ temporal (temporal point) and $800 \mu \mathrm{m}$ nasal (nasal point) to the fixation. The acquisition process was improved by changing some parameters on the control console (noise threshold level was set at $0.06 \mathrm{~V}$, and the $z$-offset and polarization controls were adjusted for each scan). Because the posterior capsule thickness varies from 4 to 9 $\mu \mathrm{m}$ in the normal human eye, ${ }^{23}$ our system could detect only a posterior capsule thickening (PCT) when total posterior capsule thickness exceeded $10 \mu \mathrm{m}$ (the axial resolution of OCT) in a single measurement of the capsule thickness in each patient. PCT was therefore detected when two reflectivity spikes appeared behind the reflectivity corresponding to the IOL. Computer software-controlled cursors were manually placed at the peak of the reflectivity spikes corresponding to the posterior capsule, and tissue thickening was calculated between the peaks from the time delay of the reflected light. Computer cursors placed at the peak of the reflectivity spikes yielded better reproducibility than placing the cursors at the beginning of the rising slopes. In addition, the peak intensities (i.e., the maximum height of the spikes in decibels), were measured at the most posterior spike of the PCO. The same assistant research technician (AA), who had extensive experience with this technique ${ }^{15,24}$ performed all measurements.

\section{Reliability Study}

A subset of 30 eyes of 30 patients underwent repeated measurements, to assess the reliability of the procedure. Intraoperator repeatability
TABLE 1. Intraoperator Repeatability and Reliability

\begin{tabular}{lcl}
\hline OCT Estimates & Repeatability* & \multicolumn{1}{c}{$\begin{array}{c}\text { Reliability† } \\
\text { (95\% CI) }\end{array}$} \\
\hline $\begin{array}{l}\text { Peak intensity (dB) } \\
\text { Temporal }\end{array}$ & 7.80 & $0.29(-0.08-0.59)$ \\
Nasal & 5.37 & $0.75(0.53-0.87)$ \\
Center & 9.99 & $0.06(-0.31-0.42)$ \\
$\quad$ Average & 5.1 & $0.59(0.3-0.78)$ \\
Posterior capsule & & \\
thickening $(\mu \mathrm{m})$ & & \\
Temporal & 27.26 & $0.96(0.92-0.98)$ \\
Nasal & 16.16 & $0.97(0.95-0.99)$ \\
Center & 37.87 & $0.88(0.77-0.94)$ \\
Average & 19.79 & $0.97(0.93-0.98)$ \\
\hline
\end{tabular}

* Intraoperator repeatability was calculated as 2.77 times the within-subject standard deviation of the two consecutive measurements for each eye. ${ }^{25}$ (ICC). ${ }^{26}$

† Reliability is calculated with the intraclass correlation coefficient was calculated after our experienced examiner acquired and analyzed two consecutive examinations from the same eye in the same session. Interoperator repeatability was assessed after the first examination obtained by our experienced examiner (operator 1 [AA]) was compared with the one acquired and analyzed from the same eye in the same session by another independent masked examiner (operator 2). Between examinations, the subject was separated from the device, and the operator left the room, so that the operator had to reposition the subject before taking another examination.

The study protocol adhered to the tenets of the Declaration of Helsinki. Participants provided written informed consent.

\section{Statistical Analysis}

Data forms were completed with the OCT values quantified at the center, nasal, and temporal locations. In addition, the averages of all three were computed. Analyses were performed on computer (SPSS, ver. 11.0; SPSS, Inc., Chicago, IL). The statistical significance was determined by the Kruskal-Wallis test, and the Mann-Whitney nonparametric test provided the nonparametric data distribution. Results are expressed as medians and interquartile ranges. Associations among study variables were analyzed by calculating the Spearman correlation coefficient.

Intraoperator repeatability was calculated as 2.77 times the withinsubject SD $(s w)$ of the two consecutive measurements for each eye. ${ }^{25}$ The difference between two measurements for the same subject is expected to be $<2.77 \times s w$ for $95 \%$ of pairs of observations. ${ }^{25}$ The

TABLE 2. Interoperator Repeatability

\begin{tabular}{|c|c|c|c|c|}
\hline \multirow[b]{2}{*}{ OCT Estimates } & \multirow[b]{2}{*}{$\underset{(t \text {-test })}{P}$} & \multirow[b]{2}{*}{$\begin{array}{c}\text { Mean } \\
\text { Difference* }\end{array}$} & \multicolumn{2}{|c|}{$\begin{array}{c}\text { Limits of } \\
\text { Agreement }\end{array}$} \\
\hline & & & Lower & Upper \\
\hline \multicolumn{5}{|l|}{ Peak intensity $(\mathrm{dB})$} \\
\hline Temporal & 0.341 & -1.22 & -14.06 & 11.61 \\
\hline Nasal & 0.096 & 2.24 & -11.50 & 15.98 \\
\hline Center & 0.093 & 1.11 & -5.77 & 7.99 \\
\hline Average & 0.115 & 0.74 & -4.18 & 5.67 \\
\hline \multicolumn{5}{|l|}{$\begin{array}{l}\text { Posterior capsule } \\
\text { thickening }(\mu \mathrm{m})\end{array}$} \\
\hline Temporal & 0.263 & 5.33 & -43.13 & 53.79 \\
\hline Nasal & 0.084 & 11.14 & -55.86 & 78.13 \\
\hline Center & 0.225 & -7.14 & -69.13 & 54.85 \\
\hline Average & 0.503 & 2.74 & -40.68 & 46.16 \\
\hline
\end{tabular}

* Mean difference between examiners. 
TABLE 3. Interoperator Concordance

\begin{tabular}{ll}
\hline \multicolumn{1}{c}{ OCT Estimates } & CCC* $(95 \%$ CI) \\
\hline $\begin{array}{l}\text { Peak intensity }(\mathrm{dB}) \\
\text { Temporal }\end{array}$ & $0.29(0.02-0.52)$ \\
Nasal & $0.24(-0.03-0.48)$ \\
Center & $0.56(0.26-0.76)$ \\
Average & $0.70(0.46-0.84)$ \\
Posterior capsule thickening $(\mu \mathrm{m})$ & \\
$\quad$ Temporal & $0.79(0.60-0.90)$ \\
Nasal & $0.58(0.32-0.75)$ \\
Center & $0.72(0.49-0.85)$ \\
Average & $0.82(0.65-0.91)$ \\
\hline
\end{tabular}

${ }^{*}$ Lin's concordance correlation coefficient (CCC). ${ }^{28}$ intraoperator reliability of the measurement method was also calculated with the intraclass correlation coefficient (ICC). ${ }^{26}$

The 95\% limits of agreement (LoA) were calculated as the average difference in measurements made by the two examiners $\pm 1.96 \mathrm{SD}$, the lower values indicating higher interoperator repeatability. ${ }^{27}$ The paired $t$-test was also used to establish whether there was any statistically significant systematic bias between measurements made by different examiners. The interoperator reliability of the measurement method was calculated with the concordance correlation coefficient described by Lin. $^{28}$

The ability of the four PCT estimates to discriminate between pearl-type and fibrosis-type $\mathrm{PCO}$ was investigated with receiver operating characteristic (ROC) curves. ${ }^{29}$ Optimal cutoff levels for pearl-type PCO detection were determined using Youden's index ( $\gamma=$ sensitivity + specificity -1$) \cdot{ }^{30,31}$ All statistical tests were two-tailed, and $\alpha$ was set at 0.05 .
A

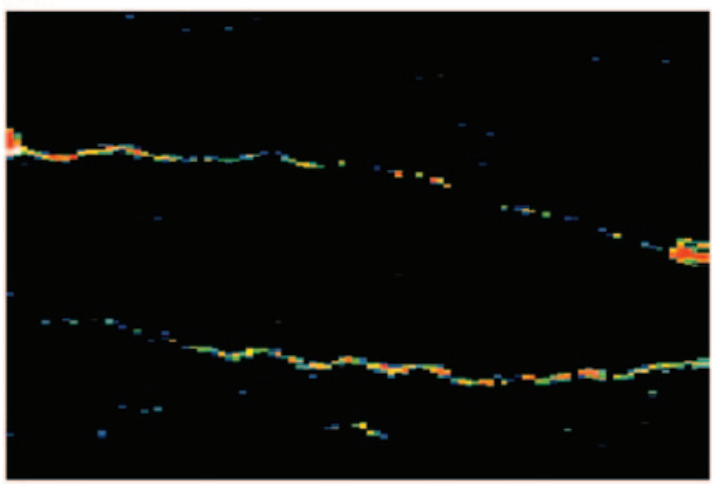

C

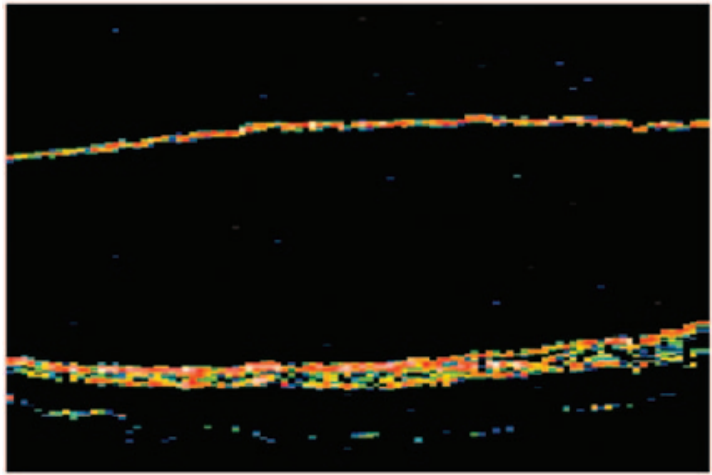

E

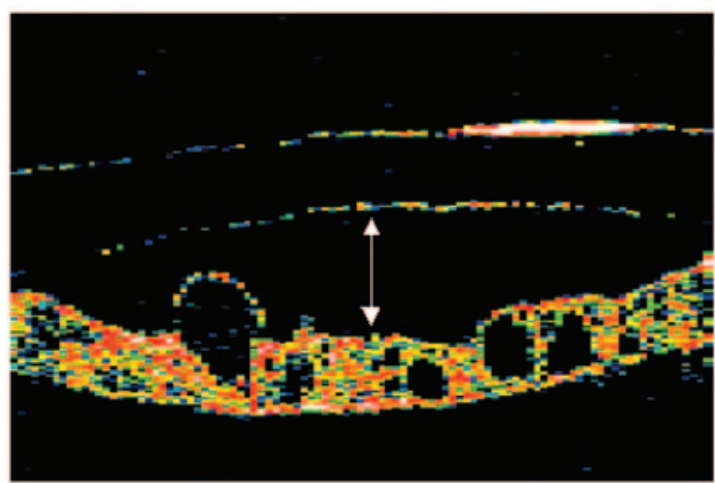

B

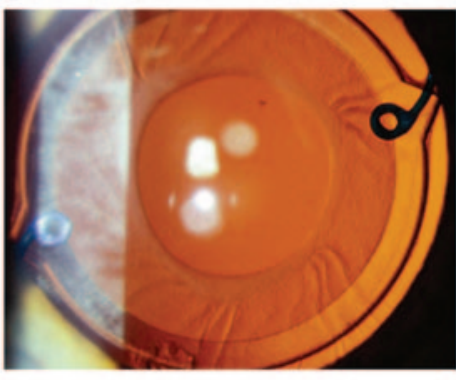

D

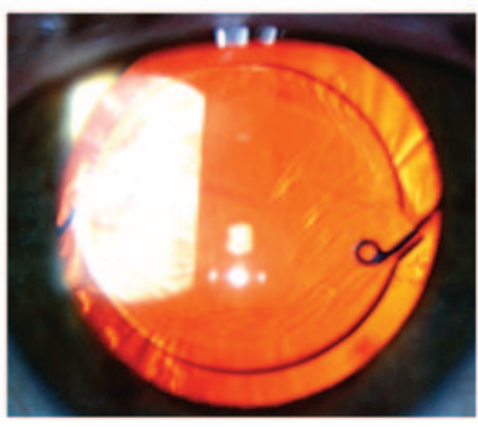

$\mathbf{F}$

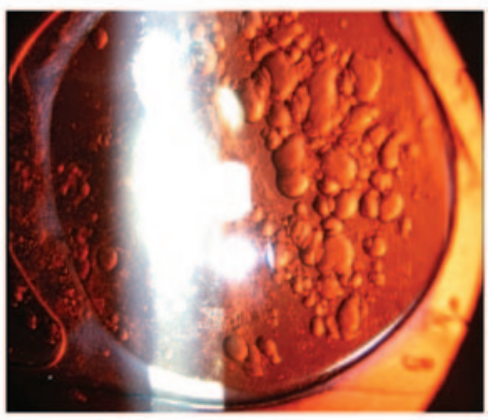
and posterior IOL surfaces and posterior capsule in the control group. (B) Slit-lamp image of a silicone IOL in the control group. (C) OCT image of fibrosis-type PCO. (D) Slit-lamp image of fibrosis-type PCO. (E) OCT image obtained in a case with pearltype PCO with a posterior concave PMMA IOL in high myopia. A gap between the posterior surface of the IOL and the posterior capsule can be seen (double-beaded arrow). The pearl-type PCO and its increased thickness are shown. (F) Slit-lamp image of the posterior capsule with pearl-type PCO. 
A

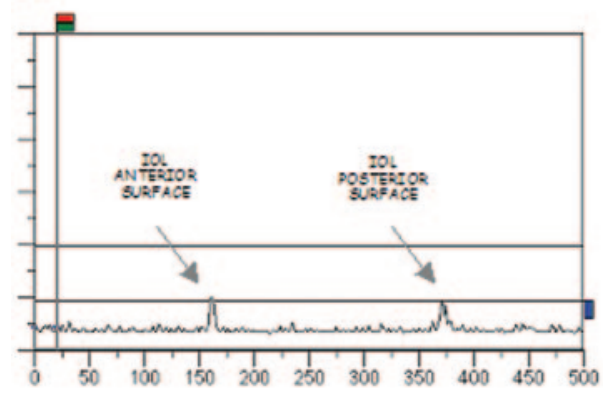

C

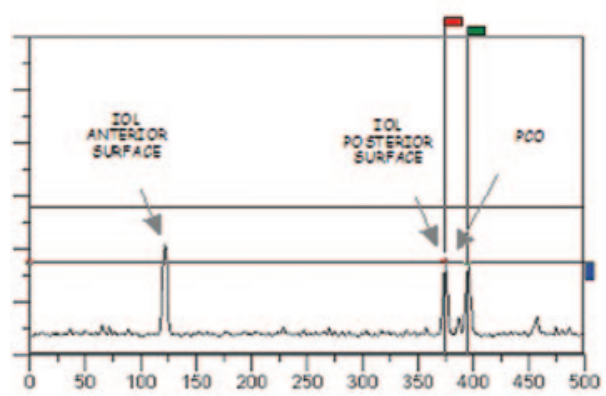

E

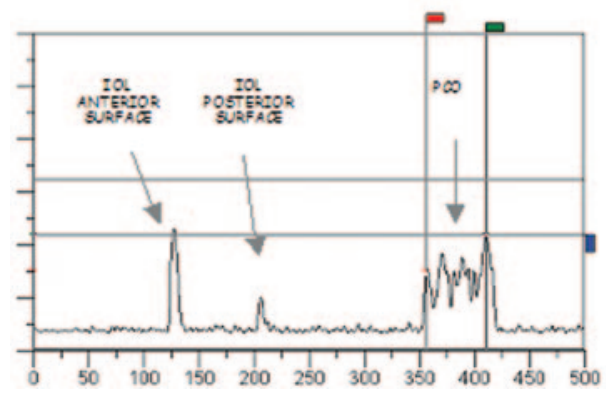

B

\begin{tabular}{|l|l|}
\hline \multicolumn{2}{|c|}{ Eye Information } \\
\hline Eye & OS \\
Eye Length & $24.46 \mathrm{~mm}$ \\
Refraction & $0.00 \mathrm{D}$ \\
At Location $==>49$ & \\
Cursor 1 value is $4.3 \mathrm{~dB}$ at 20 \\
Cursor2 value is $4.3 \mathrm{~dB}$ at 20 \\
Cursor3 value is $8.7 \mathrm{~dB}$. Offset is $10.0 \mathrm{~dB}$ \\
Difference is 0.0 ct, Distance is $0 \mu \mathrm{m}$ \\
\hline
\end{tabular}

D

\begin{tabular}{|l|}
\hline \multicolumn{1}{|c|}{ Eye Information } \\
\hline Eye $\quad$ OS \\
Eye Length $: 24.46 \mathrm{~mm}$ \\
Refraction $: 0.00 \mathrm{D}$ \\
At Location $==>69$ \\
Cursor1 value is $16.6 \mathrm{~dB}$ at 374 \\
Cursor2 value is $16.4 \mathrm{~dB}$ at 395 \\
Cursor3 value is $16.3 \mathrm{~dB}$. Offset is $10 . \mathrm{gB}$ \\
Difference is $0.2 \mathrm{~dB}$. Oistance is $84 \mu \mathrm{m}$ \\
\hline
\end{tabular}

F

\begin{tabular}{|l|l|}
\hline \multicolumn{2}{|c|}{ Eye Information } \\
\hline Eye & $\mathrm{OD}$ \\
Eye Length & $24.46 \mathrm{~mm}$ \\
Refraction & $0.00 \mathrm{D}$ \\
At Location $==>64$ \\
Cursor1 value is $14.5 \mathrm{~dB}$ at 357 \\
Cursor2 value is $208 \mathrm{~dB}$ at 411 \\
Cursor3 value is $20.6 \mathrm{~dB}$. Offset is $100 \mathrm{gB}$ \\
Difference is $6.3 \mathrm{~dB}$. Distance is $216 \mu \mathrm{m}$ \\
\hline
\end{tabular}

Figure 3. OCT peaks obtained in the same eyes as in Figure 2. (A) The anterior and posterior IOL peaks are shown in an eye without PCO. (B) The cursor 3 value $(8.7 \mathrm{~dB})$, indicates the peak intensity at the posterior capsule. (C) Scan profile in an eye with fibrosis-type PCO. The peaks corresponding to the anterior and posterior IOL surfaces are shown. In addition, the distance between the second and third peak is considered to be the PCT. (D) The distance between cursors 1 and 2 is used to measure PCT $(84 \mu \mathrm{m})$. The cursor 3 indicates the peak intensity value $(16.3 \mathrm{~dB})$. (E) This scan profile shows four major peaks: the first two correspond to the anterior and posterior IOL surfaces, respectively. The distance between the second and third peaks shows the gap between the IOL and the posterior capsule. More posteriorly, a number of peaks reflect PCO. (F) The cursors are placed on the first and the last peaks of the PCO. The distance between cursors 1 and 2 is $216 \mu \mathrm{m}$ (PCT). The cursor 3 indicates the peak intensity value of the last PCO peak (20.6 dB).

\section{Results}

\section{Reliability Study}

Intraoperator repeatability was $5.1 \mathrm{~dB}$ and $19.8 \mu \mathrm{m}$ for the average peak intensity and PCT, respectively. Table 1 shows that the average and nasal values were more repeatable internally than the central and temporal measurements for both peak intensity and PCT. Also, intraoperator reliability (ICC) was overall better for PCT measurements than for peak intensity values.

No statistically significant difference was found between both examiners' readings for both peak intensity and PCT (Table 2). LoA were moderate to wide and generally larger for point estimates than for the average of the three locations (Table 2). Concordance correlation coefficients indicated that interoperator reproducibility was generally better for PCT measurements than for peak intensity values (Table 3 ).

\section{Clinical Study}

Of the 66 eyes with PCO, 26 (39.4\%) had fibrosis-type PCO and $40(60.6 \%)$ had pearl-type PCO. The logMAR-BCVA of eyes with PCO (median, 0.39; IR, 0.22-0.69) was significantly worse than that in the control group $(P=0.001)$. In cases with fibrosis-type PCO, the logMAR-BCVA median was 0.3 (IR, $0.22-$ 0.39 ) and in cases with the pearl PCO, the median was 0.39 (IR, $0.22-0.79 ; P=0.21$ ). The median of time after surgery

TABLE 4. Comparison of Intensity Peaks of the Posterior Capsule among the Groups

\begin{tabular}{lcccc}
\hline \multicolumn{1}{c}{ Group } & Eyes $(\boldsymbol{n})$ & Temporal & Center & Nasal \\
\hline Control & 20 & $11.85(8.9-18.47)$ & $11(9.7-13.9)$ & $9.3(7.75-11.92)$ \\
Fibrosis-type & 26 & $17.5(12.75-22.9)$ & $16.1(11.9-20.65)$ & $11.9(8.58-14.28)$ \\
Pearl-type & 40 & $17(11.75-18.90)$ & $17.9(12.2-23)$ & $10.1-19.85)$ \\
$P^{*}$ & & 0.59 & 0.41 & $15.5(10.6-19.8)$ \\
0.95 & $16.85(12.75-20.52)$ \\
\hline
\end{tabular}

Data are expressed as median decibels (interquartile range).

* Comparison between groups with the fibrosis-type and pearl-type PCO (Mann-Whitney test). 
Table 5. Comparison of Posterior Capsule Thickness ( $\mu \mathrm{m}$, median and interquartile range)

\begin{tabular}{|c|c|c|c|c|c|}
\hline Group & Eyes $(n)$ & Temporal & Center & Nasal & Average \\
\hline Control & 20 & 0 & 0 & 0 & 0 \\
\hline Fibrosis-type & 26 & $38(27-81)$ & $30(19-81)$ & $28(11-85)$ & $34.66(17.33-74.66)$ \\
\hline Pearl-type & 40 & $90(76-151)$ & $100(76-152)$ & $98(72-151)$ & $100.66(78.66-146)$ \\
\hline$P^{*}$ & & 0.001 & 0.001 & 0.001 & 0.001 \\
\hline
\end{tabular}

Data are expressed as the median micrometers (interquartile range).

* Comparison between groups with fibrosis-type and pearl-type PCO (Mann-Whitney test).

was 36 months (IR, 23-47.25) in eyes with PCO and 23 months (IR, 3.25-58.75) in the control group $(P=0.19)$.

Images obtained from the groups based on opacification type are shown in Figures 2 and 3. The median intensities of the reflectivity spikes were $16.88 \mathrm{~dB}$ (IR, 12.88-20.41) in PCO eyes and $11.9 \mathrm{~dB}$ (IR, 8.58-14.28) in the control group $(P=$ 0.001). The average PCO intensities at the three measurement points are shown in Table 4 . No significant differences in the three points and the average intensities were found when the two PCO types were compared.

PCT could not be measured in control eyes, because only one peak occurred. In the PCO group, the median PCT was 83.16 $\mu \mathrm{m}$ (IR, 46.33-115.33; $P=0.001$ compared with the control group). There was a significant difference $(P=0.001)$ in the PCT between the groups with the fibrosis-type and the pearl-type PCO (Table 5).

The correlation between BCVA and PCT (Fig. 4) was statistically significant $\left(r_{\mathrm{o}}=0.66 ; 95 \% \mathrm{CI}, 0.51-0.76 ; P=0.001\right)$. No significant relationship was obtained between BCVA and PCO intensity $\left(r_{\mathrm{o}}=0.1 ; 95 \% \mathrm{CI}, 0.34\right.$ to $-0.15 ; P=0.42$; Fig. $5)$. Time after surgery did not correlate with either PCT $\left(r_{\mathrm{o}}=\right.$ $0.22 ; 95 \% \mathrm{CI}, 0.44$ to $-0.03 ; P=0.08)$, PCO intensity $\left(r_{\mathrm{o}}\right.$ $=-0.13 ; 95 \% \mathrm{CI}, 0.12$ to $-0.37 ; P=0.30)$, or BCVA $\left(r_{\mathrm{o}}=\right.$ -0.16 ; $95 \%$ CI, 0.40 to $-0.09 ; P=0.21$; Fig. 6 ).

Classification accuracy for pearl-type PCO as opposed to fibrosis-type PCO is shown in Table 6. The average PCT had the ROC curve with the highest diagnostic value and represents the best discriminator between pearl-type and fibrosistype PCO (Fig. 7). Its AUC was 0.872. The maximum Youden's index of average PCT was 0.67 corresponding to a cutoff level of $55.3 \mu \mathrm{m}$ (Table 7). Sensitivity and specificity for this cutoff point were $97.5 \%$ and $69.2 \%$, respectively.

\section{Discussion}

PCO evaluation is important for measuring the effect of IOL designs or biocompatibility, pharmaceutical treatments, and

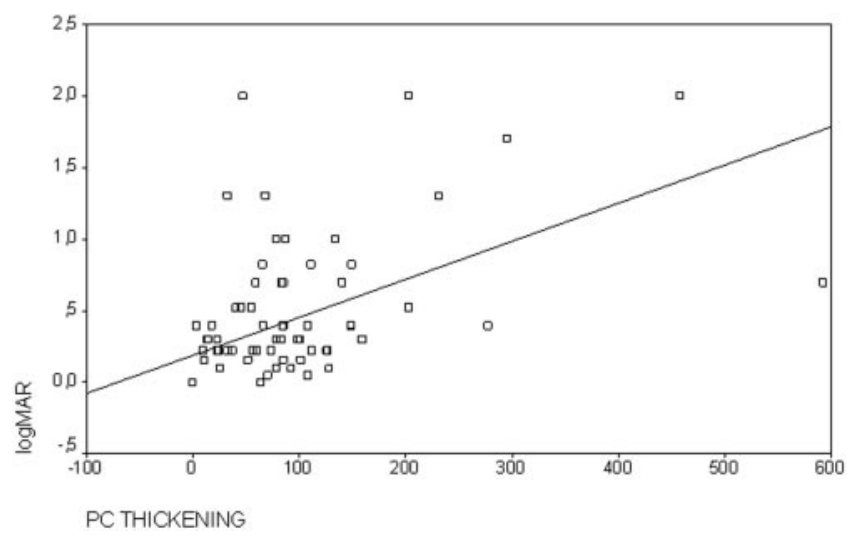

FigURE 4. Scatterplot of PCT increase versus logMAR best-corrected visual acuity (Spearman correlation $=0.66$ ). variations in cataract surgery techniques. The ideal system of evaluation should be objective, easy to perform, have minimal bias, be sufficiently sensitive to calculate small PCO variations, and produce a quantifiable PCO value that correlates well with VA changes. ${ }^{32}$

Different methods of PCO evaluation have been reported that are either qualitative or quantitative. Qualitative methods, such as slit lamp grading evaluation and fundus visualization, can illustrate PCO but are subjective and have difficulty calculating PCO evolution. ${ }^{32}$

Recently, new methods of PCO quantitative evaluation have been reported. ${ }^{12,32-34}$ No one system is considered a gold standard, and each has advantages and disadvantages. Scheimpflug videophotography has been used to provide reproducible, objective, and quantitative measurements of PCO that have good correlation with VA. ${ }^{35-37}$ However, the intensity of PCO quantified by Scheimpflug videophotography cannot be compared with different IOL materials, ${ }^{38}$ and this system is not readily available to most eye centers. ${ }^{32}$ Overall, digital photographic image acquisition systems allow access to computerized analysis, which can reduce observer bias and increase accuracy. ${ }^{32}$ Brightness-based analysis, however, is little used because of the abundance of potential error sources (variations in background intensity and in illumination). ${ }^{32}$ Computerized analyses of density boundaries such as the EPCO 2000 (a software program developed by Manfred Tetz and Christophe Nimsgern, Universitats-Augenklinik Charite, Berlin, Germany) and the POCO (posterior capsule opacification) systems analyze a wide area of the posterior capsule, but appear not to be fully objective in that they rely on the human operator to assess the PCO levels in different areas of the digital computer image. ${ }^{32,39}$ Texture analysis is regarded to be the nearest to a fully objective system for analysis. ${ }^{32,40}$ However, the specialized equipment is not available for general use. ${ }^{32}$ The color-coded grid system is freely available, but appears to be

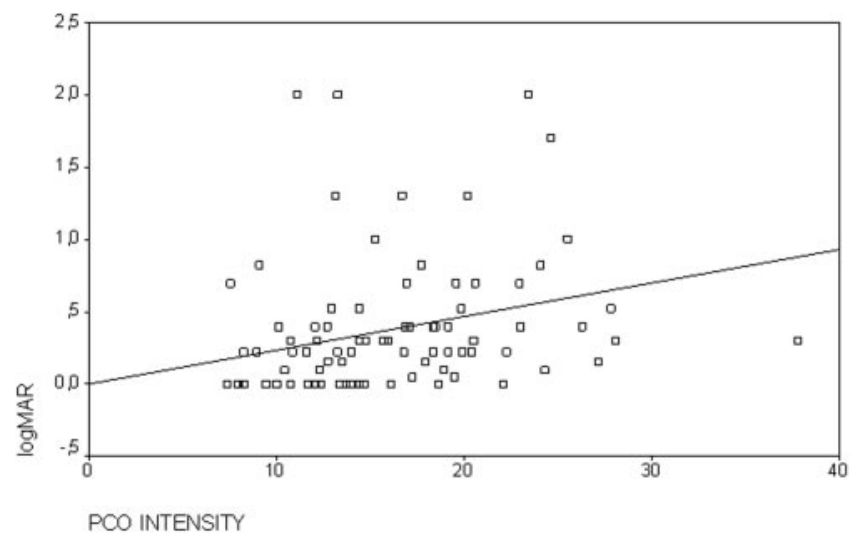

Figure 5. Posterior capsule intensity plotted against best-corrected visual acuity in logMAR units (Spearman correlation $=0.1 ; n=86$ ). 


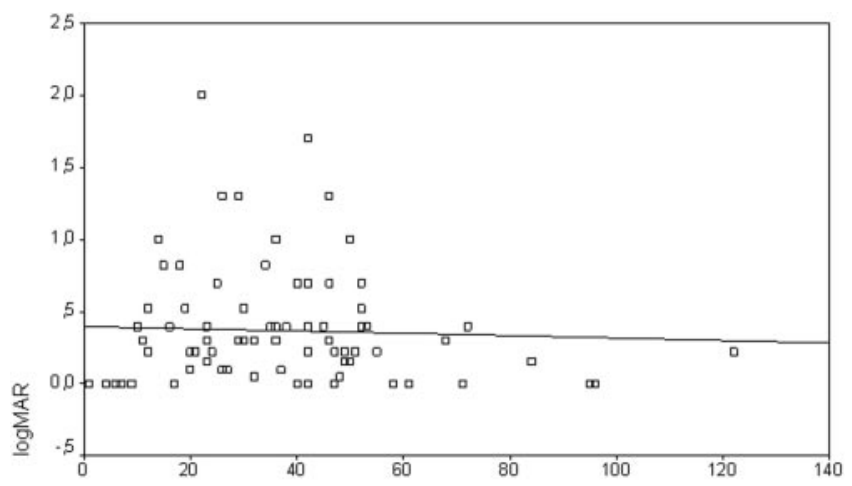

FOLLOW-UP AFTER SURGERY

FiguRE 6. Relationship between best-corrected visual acuity (logMAR) and the time after cataract surgery (in months). In five cases with PCO, the patient was operated on elsewhere, and it was impossible to know the elapsed time after surgery $(n=81)$.

less objective than the POCO system and has not been extensively tested in clinical trials. ${ }^{32}$

In this study, we present a new way to evaluate PCO using OCT-1. Although OCT is becoming increasingly available to many eye centers, to the best of our knowledge, there have been no previous reports using OCT to study PCO. OCT, which uses a low-coherence light without causing patient discomfort by flashes of light, provide real-time imaging of the posterior capsule. Until now, we have been able to obtain cross-sectional measurements that enable quantification of PCT using the above-mentioned technique, which is not completely automated. However, despite not analyzing a wide area, we found a good correlation of PCO values with VA, in an analogous way as reported for the Scheimpflug system, ${ }^{35}$ and the PCT measurements were very reliable internally. Previous studies involving OCT also have shown good reproducibility of retinal and corneal measurements. ${ }^{15,41,42}$

Intraoperator repeatability of OCT PCO quantification was shown in Table 1 to be generally good. It has been recommended that an ICC should exceed 0.90 if a technique is to be used for individual assessments in clinical practice and 0.70 for discriminating among groups in research. ${ }^{43}$ Most PCT estimates qualified therefore for both modalities, however, only central peak intensity values maybe used, and solely for the latter.

Although no significant systematic bias was found between both operators, the limits of agreement tended to be overall wide and clinically relevant (Table 2 ). This can be explained because none of the technicians at our institution was as experienced using OCT as operator $1 .^{15,24} \mathrm{De}$ spite this limitation, Lin's concordance correlation coefficient $^{28}$ indicated good and acceptable interoperator repeatability for the average PCT and peak intensity, respectively (Table 3).

Two OCT types of measurements were obtained from the PCO: the intensity of the peaks and the distance between two peaks at the posterior capsule. To the best of our knowledge, this is the first time that an objective estimate of PCO thickness was quantified in living human eyes. With OCT, each reflectivity peak is created when the tissue structure changes. If only one peak occurs, the PCO thickness cannot be measured accurately because the OCT resolution $(10 \mu \mathrm{m})^{12,43}$ exceeds normal posterior capsule thickness, which ranges from 4 to 9 $\mu \mathrm{m}$ and shows no significant changes with age. ${ }^{23}$ If two peaks are obtained in the PCO, the first is produced by the reflective change between the IOL material and the posterior capsule,
TABLE 6. Area under the ROC Curve for Differentiating Pearl-Type from Fibrosis-Type PCO, According to PCT as Measured by OCT

\begin{tabular}{lccc}
\hline PCT Measure & $\begin{array}{c}\text { Area under } \\
\text { ROC Curve }\end{array}$ & $\mathbf{9 5 \%} \mathbf{C I}$ & $\boldsymbol{P}^{*}$ \\
\hline Central & 0.868 & $0.771-0.964$ & 0.001 \\
Nasal & 0.825 & $0.712-0.938$ & 0.001 \\
Temporal & 0.808 & $0.694-0.922$ & 0.001 \\
Averaget & 0.872 & $0.776-0.968$ & 0.001 \\
\hline
\end{tabular}

$n=66$

* Statistical significance of the area under the ROC curve.

† Average of the central, nasal, and temporal measures of PCT.

and the second results from the reflective change between the posterior capsule and vitreous. Thus, the distance between the two peaks can be considered the PCT, given the OCT axial resolution. ${ }^{12,42}$

Cheng et al. ${ }^{19}$ showed that patients with pearl-type PCO had worse VA and contrast sensitivity than those with fibrosis-type PCO. They suggested that the fibrosis-type PCO attenuates light, whereas the pearl-type PCO primarily causes light-scattering and superimposes a forward veiling light on the retina, reducing the contrast of retinal images. Thus, the more scattered the light, the greater the reductions in VA and contrast sensitivity. ${ }^{19}$ Our results indicated that the BCVA was lower in eyes with the pearl-type PCO and also that in those eyes the PCO was thicker than in those with the fibrosis-type PCO. We found a significant relationship between BCVA and PCO thickness, but no correlations between BCVA and peak intensity or between BCVA and the time after surgery. These results suggest that PCO thickness is an important factor that causes decreased VA. This observation is consistent with the clinical experience in some eyes in which faint fibrosis is observed immediately after cataract surgery without a decrease in BCVA. However, because we did not measure contrast sensitivity, the relationship between visual function and PCO thickness must be considered cautiously.

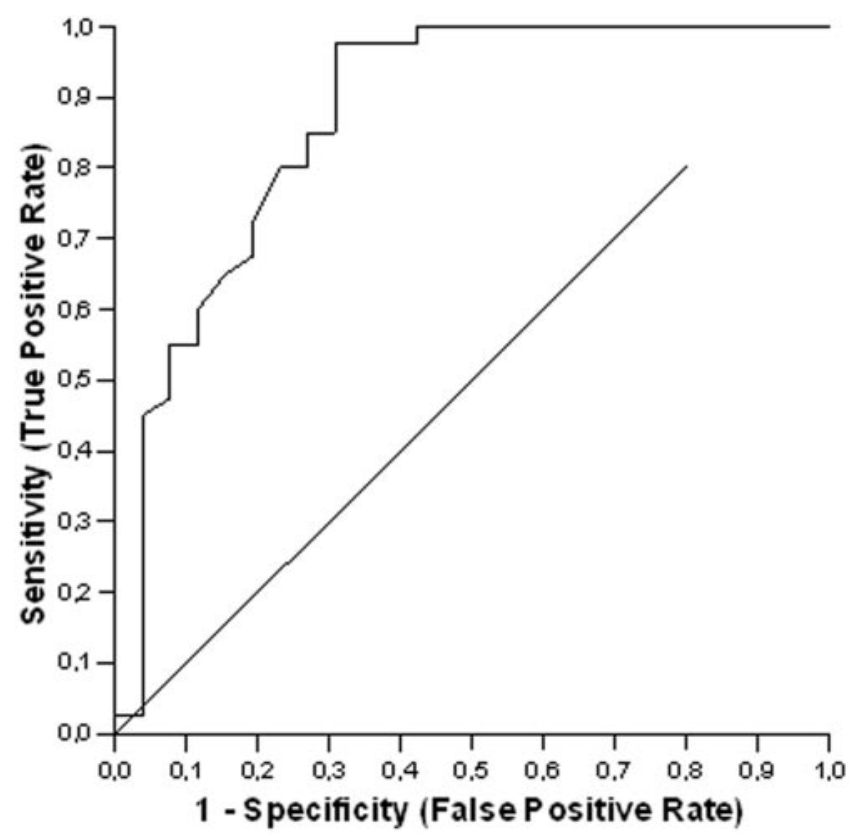

Figure 7. ROC for average PCT by OCT used to identify pearl-type PCO (as opposed to fibrosis-type PCO), $n=86$. 
TABLE 7. Sensitivity and Specificity of PCT, by OCT to Differentiate Pearl-Type from Fibrosis-Type PCO

\begin{tabular}{lcccr}
\hline PCT Measure & $\begin{array}{c}\text { Cutoff } \\
(\geq \boldsymbol{\mu m})^{*}\end{array}$ & $\begin{array}{c}\text { \% Sensitivity } \\
(\mathbf{9 5 \%} \mathbf{C I})\end{array}$ & $\begin{array}{c}\text { \% Specificity } \\
\text { (95\% CI) }\end{array}$ & $\begin{array}{c}\text { Youden's Indext } \\
(\mathbf{9 5 \%} \text { CI) }\end{array}$ \\
\hline Central & 56.0 & $92.5(80.9-98.0)$ & $73.1(53.9-87.4)$ & $0.66(0.47-0.84)$ \\
Nasal & 46.0 & $95.0(84.5-99.6)$ & $65.4(45.9-81.6)$ & $0.60(0.41-0.80)$ \\
Temporal & 46.0 & $90.0(77.6-96.7)$ & $73.1(53.9-87.4)$ & $0.63(0.44-0.82)$ \\
Average $\neq$ & 55.3 & $97.5(88.3-99.9)$ & $69.2(49.8-84.6)$ & $0.67(0.48-0.85)$ \\
\hline
\end{tabular}

$n=66$

${ }^{*}$ Cutoff point balancing sensitivity and specificity in diagnosing pearl-type PCO (as opposed to fibrosis-type) according to the maximum Youden's index.

† Youden's index $(\gamma=$ sensitivity + specificity -1$){ }^{25-27}$

‡ Average central, nasal, and temporal PCT measures.

Because we believe that OCT may play a role in clinical research, discriminating the two types of PCO by OCT alone would be interesting, because it would allow technicians to collect data in large samples of patients for transverse and longitudinal studies without the need to have an ophthalmologist examine each eye. The AUC was then used to measure diagnostic performance of PCT by OCT in differentiating pearl-type from fibrosis-type PCO. Measurements discriminated fairly well between both PCO types (Table 6). Overall, the sensitivity was high and specificity was fair for each of the PCT estimates. Specifically, the average PCT cutoff value of $55.3 \mu \mathrm{m}$ showed a tolerable balance between sensitivity and specificity, which make it a useful objective tool for detecting pearl-type PCO, a relevant aspect given the meaningful visual and recurrence rate implications of this type of PCO. ${ }^{19}$

This study had several limitations. First, the OCT tissue thickness is calculated between two points from the timedelay of reflected light by assuming a constant refractive index of $1.36 .{ }^{13}$ The fact that the posterior capsule tissue refractive index is slightly different $(1.40)^{23}$ from the retinal refractive index ${ }^{13}$ may indicate that the measurements are approximate but not exact. However, for comparison and objective analysis, OCT appears useful for measuring PCT, as it has been for measuring corneal thickness. ${ }^{15,44}$ The peak intensity was obtained from the second peak, but other lower peaks inside the PCO thickness were not considered because of the inherent difficulty in measuring them accurately from the baseline values and the mathematical analysis of many points. There were a small number of patients with PCO, because the inclusion criteria were restrictive. In addition, three points were measured and not the full posterior capsule. However, the three points covered a width of $1.6 \mathrm{~mm}$ located centrally. This area, although limited, has more impact on visual function, and in fact measurements correlated with VA. Nevertheless, more specific software that would analyze a wider area is desirable and may become a reality, as it has with retinal mapping. ${ }^{21}$ Despite these limitations, the OCT technique was easy to perform and noninvasive, allowed quantitative analysis of PCO, especially of PCT, and the results were consistent with the results of other methods of PCO evaluation. ${ }^{19,29}$ For these reasons, we believe that this study is a valuable contribution to PCO research.

In summary, OCT-1 produced an objective estimate of PCO intensity and thickness. The intraoperator repeatability of the PCO measurements was moderate for peak intensity estimates and excellent for PCT estimates, which make them useful for discriminating among groups in research. Interoperator repeatability was notably lower, which should be improved by equaling the experience of different examiners using OCT for these purposes. This system also discriminated between pearl-type and fibrosis-type PCO. The rela- tionship between the BCVA and the PCT suggests that the PCO thickness is a meaningful, and to the best of our knowledge, previously unrecognized factor in decreased VA. Future refinements of this technique will allow more detailed investigation of other characteristics of PCO (with resolutions $<10 \mu \mathrm{m}$ ), and new OCT software similar to the retinal map software may be able to draw a full map of the PCT. ${ }^{21}$ Preliminary analysis indicates that this is a valuable tool in both clinical and research settings.

\section{Acknowledgments}

The authors thank Marta García-Granero, MS, for valuable suggestions and assistance provided in the statistical analysis of the data.

\section{References}

1. Cobo LM, Ohsawa E, Chandler D, Arguello R, George G. Pathogenesis of capsular opacification after extracapsular cataract extraction: an animal model. Ophthalmology. 1984;91:857-863.

2. Apple DJ, Peng Q, Visessook N, et al. Surgical prevention of posterior capsule opacification. Part 1: progress eliminating this complication of cataract surgery. J Cataract Refract Surg. 2000; 26:180-187.

3. Peng Q, Apple DJ, Visessook N, et al. Surgical prevention of posterior capsule opacification. Part 2: enhancement of cortical cleanup by focusing on hydrodissection. J Cataract Refract Surg. 2000;26:188-197.

4. Peng Q, Visessook N, Apple DJ, et al. Surgical prevention of posterior capsule opacification. Part 3: intraocular lens optic barrier effect as a second line of defense. J Cataract Refract Surg. 2000;26:198-213.

5. Yamada K, Nagamoto T, Yozawa H, et al. Effect of intraocular lens design on posterior capsule opacification after continuous curvilinear capsulorrhexis. J Cataract Refract Surg. 1995;21:697-700.

6. Nagamoto T, Eguchi G. Effect of intraocular lens design on migration of lens epithelial cells onto the posterior capsule. J Cataract Refract Surg. 1997;23:866-872.

7. Menapace R. Posterior capsule opacification and capsulotomy rates with taco-style hydrogel intraocular lenses. $J$ Cataract Refract Surg. 1996;22:1318-1330.

8. Wang M-C, Woung L-C. Digital retroilluminated photography to analyze posterior capsule opacification in eyes with intraocular lenses. J Cataract Refract Surg. 2000;26:56-61.

9. Schaumberg DA, Dana MR, Christen WG, Glynn RJ. A systematic overview of the incidence of posterior capsule opacification. $O p b$ thalmology. 1998;105:1213-1221.

10. Mamalis N, Crandall AS, Linebarger E, Sheffield WK, Leidenix MJ. Effect of intraocular lens size on posterior capsule opacification after phacoemulsification. J Cataract Refract Surg. 1995;21:99102.

11. Duncker GIW, Westphalen S, Behrendt S. Complications of silicone disc intraocular lenses. J Cataract Refract Surg. 1995;21: 562-566.

12. Izatt JA, Hee MR, Swanson EA, et al. Micrometer-scale resolution imaging of the anterior eye in vivo with optical coherence tomography. Arch Ophthalmol. 1994;112:1584-1589. 
13. Puliafito CA, Hee MR, Lin CP, et al. Imaging of macular diseases with optical coherence tomography. Ophthalmology. 1995;102: 217-229.

14. Schuman JS, Pedut-Kloizman T, Hertzmark E, et al. Reproducibility of nerve fiber layer thickness measurements using optical coherence tomography. Ophthalmology. 1996;103:1889-1898.

15. Maldonado MJ, Ruiz-Oblitas L, Munuera JM, Aliseda D, GarcíaLayana A, Moreno-Montañés J. Optical coherence tomography evaluation of the corneal cap and stromal bed features after laser in situ keratomileusis for high myopia and astigmatism. Ophthalmology. 2000;107:81-88.

16. Nozaki M, Kimura H, Kojima M, Ogura Y. Optical coherence tomographic findings of the anterior segment alter nonpenetrating deep sclerectomy. Am J Ophthalmol. 2002;133:837-839.

17. Wang J, Fonn D, Simpson TL, Jones L. Precorneal and pre- and postlens tear film thickness measured indirectly with optical coherence tomography. Invest Ophthalmol Vis Sci. 2003;44:25242528.

18. Wirbelauer C, Winkler J, Scholz C, Haberle H, Pham DT. Experimental imaging of intracorneal ring segments with optical coherence tomography. J Refract Surg. 2003;19:367-371.

19. Cheng ChY, Yen MY, Chen SJ, Kao SCh, Hsu WM, Liu JH. Visual acuity and contrast sensitivity in different types of posterior capsule opacification. J Cataract Refract Surg. 2001;27:1055-1060.

20. Apple DJ, Solomon KD, Tetz MR, et al. Posterior capsule opacification. Surv Ophthalmol. 1992;37:73-116.

21. Hee MR, Puliafito CA, Duker JS, et al. Topography of diabetic macular edema with optical coherence tomography. Ophthalmology. 1998; $105: 360-370$.

22. Hee MR, Puliafito CA, Wong C, et al. Quantitative assessment of macular edema with optical coherence tomography. Arch Ophthalmol. 1995;113:1019-1029.

23. Krag S, Andreassen TT. Mechanical properties of the human posterior lens capsule. Invest Ophthalmol Vis Sci. 2003;44:691-696.

24. Sánchez-Tocino H, Alvarez A, Maldonado MJ, Moreno-Montañés J, García-Layana A. Retinal thickness study with optical coherence tomography in patients with diabetes. Invest Ophthalmol Vis Sci. 2002; $43: 1588-1594$.

25. Bland JM, Altman DG. Measurement error. BMJ. 1996;313:744.

26. Bland JM, Altman DG. Measurement error and correlation coefficients. BMJ. 1996;313:41-42.

27. Bland M. An Introduction to Medical Statistics. 3rd ed. Oxford, UK: Oxford University Press; 2000:268-275.

28. Lin LI. A concordance correlation coefficient to evaluate reproducibility. Biometrics. 1989;45:255-268.

29. Campbell G. General methodology. I: advances in statistical meth- odology for the evaluation of diagnostic and laboratory tests. Stat Med. 1994;12:499-508.

30. Youden WJ. An index for rating diagnostic tests. Cancer. 1950;3: 32-35.

31. Hilden J, Glasziou P. Regret graphs, diagnostic uncertainty and Youden's Index. Stat Med. 1996;15:969-986.

32. Aslam TM, Dillon B, Werghi N, Taguri A, Wadood A. Systems of analysis of posterior capsule opacification. Br J Ophthalmol. 2002; 86:1181-1186.

33. Camparini M, Macaluso C, Reggiani L, Maraini G. Retroillumination versus reflected-light images in the photographic assessment of posterior capsule opacification. Invest Ophthalmol Vis Sci. 2000; 41:3074-3079.

34. Friedman DS, Duncan DD, Munoz B, West SK, Schein OD. Digital image capture and automated analysis of posterior capsular opacification. Invest Ophthalmol Vis Sci. 1999;40:1715-1726.

35. Hayashi K, Hayashi H, Nakao F, et al. In vivo quantitative measurement of posterior capsule opacification after extracapsular cataract surgery. Am J Ophthalmol. 1998;125:837-843.

36. Tobari I, Iwaki Y, Miyake K. Effect of tranilast eyedrops in preventing posterior capsule opacification: preliminary study. $J$ Cataract Refract Surg. 1999;25:1394-1399.

37. Hayashi H, Hayashi K, Nakao F, Hayashi F. Quantitative comparison of posterior capsule opacification after polymethylacrylate, silicone, and soft acrylic intraocular lens implantation. Arch Ophthalmol. 1998;116:1579-1582.

38. Tanaka Y, Kato S, Miyata K, et al. Limitation of Scheimpflug videophotography system in quantifying posterior capsule opacification after intraocular lens implantation. Am J Ophthalmol. 2004; $137: 732-735$

39. Tetz MR, Sperker M, Blum M, et al. Klinische Nachstarbewertung in pseudophaken Augen; Methode und Reproduzierbarkeit. $O p b$ thalmologe. 1996;93:33-37.

40. Barman SA, Hollick EJ, Boyce JF, et al. Quantification of posterior capsular opacification in digital images after cataract surgery. Invest Ophthalmol Vis Sci. 2000;41:3882-3892.

41. Hrynchak P, Simpson T. Optical coherence tomography: an introduction to the technique and its use. Optom Vis Sci. 2000;77:347-356.

42. Blumenthal EZ, Williams JM, Weinreb RN, Girkin CA, Berry CC, Zangwill LM. Reproducibility of nerve fiber layer thickness measurements by use of optical coherence tomography. Ophthalmology. 2000;107:2278-2282.

43. Shrout PE, Fleiss JL. Intraclass correlations: uses in assessing rater reliability. Psychol Bull. 1979;86:420 - 428.

44. Muscat S, McKay N, Parks S, Kemp E, Keating D. Repeatability and reproducibility of corneal thickness measurements by optical coherence tomography. Invest Ophthalmol Vis Sci. 2002;43:1791-1795. 